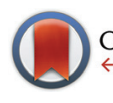

CrossMark \&lick for updates

Cite this: Dalton Trans., 2014, 43 13349

Received 23rd May 2014

Accepted 23rd July 2014

DOI: 10.1039/c4dt01518e

www.rsc.org/dalton

\title{
Preparation and properties of a calcium(II)-based molecular chain decorated with manganese(II) butterfly-like complexes $\dagger$
}

\author{
A. C. Benniston, ${ }^{\star a}$ S. Melnic, ${ }^{{ }^{b}}$ C. Turta, ${ }^{\mathrm{b}}$ A. B. Arauzo, ${ }^{\mathrm{c}}$ J. Bartolomé, ${ }^{\star d}$ \\ E. Bartolomé, ${ }^{e}$ R. W. Harrington ${ }^{f}$ and M. R. Probert ${ }^{f}$
}

\begin{abstract}
The room temperature reaction of $\left[\mathrm{Mn}_{2} \mathrm{O}_{2}(\text { bipy })_{4}\right]\left(\mathrm{ClO}_{4}\right)_{3}$ (bipy $=2,2^{\prime}$ - bipyridine) with $\mathrm{Ca}\left(\mathrm{CHCl}_{2} \mathrm{COO}\right)_{2}$ in methanol produced a yellow crystalline material. The X-ray determined structure comprises of a multiple calcium(॥) carboxylate bridged chain-like structure which is decorated with $\left[\mathrm{Mn}(\mathrm{bipy})_{2}\left(\mathrm{OH}_{2}\right)\right]^{2+}$ subunits. The redox behaviour for the complex in $\mathrm{H}_{2} \mathrm{O}$ and $\mathrm{MeCN}$ is reported. In the latter solvent the oxidation of the manganese ions appears to be facilitated by the presence of the calcium ions. Magnetic susceptibility and low temperature magnetization measurements show that the $\mathrm{Mn}$ moment is isotropic, with $g=$ 1.99(1) and $S=5 / 2$, confirming it is in the $2+$ oxidation state. A very weak antiferromagnetic interaction is also detected. Frequency-dependent ac measurements evidence slow magnetic relaxation of the $\mathrm{Mn}(\text { bipy })_{2}$ units. Two relaxation mechanisms are identified: a very slow direct process and a faster one caused by the Resonant Phonon Trapping mechanism. This is the first example of field-induced single ion magnet (SIM) behavior in a mononuclear Mn(II) complex.
\end{abstract}

\section{Introduction}

Nature over billions of years of evolution has harnessed the properties of readily abundant metals for performing indispensable biological functions. ${ }^{1}$ Intricate molecular machinery was developed to undertake reactions that under normal conditions were either extremely slow or required molecules to be activated in some manner. ${ }^{2}$ For example, carboxy peptidase is representative of the zinc(II)-based metalloenzyme which facilitates the hydrolysis of C-terminal amino acids from peptide substrates. ${ }^{3}$ Under normal physiological conditions the rate of the reaction is extremely slow because of the robust nature of

\footnotetext{
${ }^{a}$ Molecular Photonics Laboratory, School of Chemistry, Newcastle University, Newcastle upon Tyne, NE1 7RU, UK. E-mail: a.c.benniston@ncl.ac.uk

${ }^{b}$ Institute of Chemistry, Academy of Sciences of Moldova, Academiei street 3, MD-2028 Chisinau, Moldova

${ }^{c}$ Servicio de Medidas Físicas, Universidad de Zaragoza, Pedro Cerbuna 12, 50009 Zaragoza, Spain

${ }^{d}$ Instituto de Ciencia de Materiales de Aragón and Departamento de Física de la Materia Condensada, CSIC-Universidad de Zaragoza, Pedro Cerbuna 12, 50009 Zaragoza, Spain

${ }^{e}$ Escola Universitària Salesiana de Sarrià (EUSS), Passeig Sant Joan Bosco 74, 08017 Barcelona, Spain

${ }^{f}$ Crystallography Laboratory, School of Chemistry, Newcastle University, Newcastle upon Tyne, NE1 TRU, UK

$\dagger$ Electronic supplementary information (ESI) available: X-ray data for MC. CCDC 1004697. For ESI and crystallographic data in CIF or other electronic format see DOI: $10.1039 / \mathrm{c} 4 \mathrm{dt} 01518 \mathrm{e}$
}

the amide bond. The activation of carbon dioxide, again by zinc(II), in human carbonic anhydrase II is very much representative of how a relatively inactive molecule can be converted extremely quickly $\left(10^{6} \mathrm{~s}^{-1}, \mathrm{pH} 9,25{ }^{\circ} \mathrm{C}\right)$ into the bicarbonate anion. ${ }^{4}$ In these two cases, evidently the redox chemistry of the metal ion is unimportant, and it is the zinc(II) ion interaction with the substrate that is partly responsible for driving the reaction. The converse is redox-based reactions and the need for the metal ion to alter oxidation state, and the surrounding amino acid ligands in the peptide to facilitate any structural alterations (e.g., bond length changes). ${ }^{5}$ Some relevant enzyme examples include superoxide dismutase, ${ }^{6}$ peroxidases, ${ }^{7}$ catalases, ${ }^{8}$ oxidases ${ }^{9}$ and oxygenases. ${ }^{10}$ Knowledge of the structure of the active site and the periphery amino acid residues for many of the outlined peptide-based structures has helped in understanding the workings of the enzymes. ${ }^{11}$ There are obviously examples of enzymes for which the structure of the active site is unknown, or clouded by uncertainty because of the low structural resolution from the X-ray data. The water oxidation catalyst (WOC) found in photosystem II is certainly a structure which has been surrounded by controversy. ${ }^{12}$ The structure determined by Barber and co-workers ${ }^{13}$ has recently been supplanted by a more detailed analysis to $1.9 \AA$ resolution by Umena and co-workers. ${ }^{14}$ All the metal ions and ligands are uniquely located in the renowned manganese cluster comprising $\mathrm{Mn}_{4} \mathrm{CaO}_{5}$. The cube-like structure contains three manganese ions with the final site taken up by a calcium 
ion. The additional manganese ion is located outside the cubane. The linking units are oxo bridges. The cluster performs the essential sacrificial oxidation of water to generate dioxygen and protons. ${ }^{15}$ Because it is not possible to isolate the cluster outside its protective amino acid rich enzyme shell, attempts have been made to produce heterometallic $\mathrm{Mn}-\mathrm{Ca}$ clusters to mimic the WOC center. ${ }^{16}$ Some pertinent examples of WOC mimics were produced by the groups of Christou, ${ }^{17}$ Milios $^{18}$ and Agapie. ${ }^{19}$ In efforts to construct heterometallic $\mathrm{Mn}-\mathrm{Ca}$ clusters our attention focussed on using preorganised $\left[\mathrm{Mn}_{2} \mathrm{O}_{2}(\text { bipy })_{4}\right]\left(\mathrm{ClO}_{4}\right)_{3}$ (bipy $=2,2^{\prime}$-bipyridine) with the intention of forming an accretion with $\mathrm{Ca}\left(\mathrm{CHCl}_{2} \mathrm{COO}\right)_{2}$. It transpired that a calcium carboxylate-based chain was formed and dotted along its framework are $\left[\mathrm{Mn} \text { (II)(bipy) }{ }_{2} \mathrm{OH}_{2}\right]^{2+}$ subunits. The redox behaviour for the assembly appears to be affected by the presence of the calcium(II) ions, but not because of their Lewis acid property. As well as being able to focus on the electrochemical properties of the assembly, the incorporation of paramagnetic $\mathrm{Mn}$ (II) ions into the molecular framework also opened up the opportunity to study its magnetic properties. Magnetic dynamic behaviour of the Mn(II) units is of interest in the context of new mononuclear transition metal compounds with single-ion magnet (SIM) behaviour. Although mixed-valence manganese clusters have been reported to exhibit single-molecule magnet $(\mathrm{SMM})^{20,21}$ properties, there are only a few recent examples of Mn-based SIMs. ${ }^{22-24}$ It turned out that the new assembly displayed SIM behavior despite the expected low anisotropy $(S=5 / 2, L=0)$.

\section{Results and discussion}

\section{Synthesis}

There is no steadfast method for constructing extensive mixedmetal ion structures, especially in which active metal ion(s) should be in close proximity to a potential reactive site. Rather than applying a hit-and-miss approach one of our main molecular design criteria was to utilise the diverse binding motif of the carboxylate group. The functional group has served many other groups in their quest to fabricate supramolecular structures. ${ }^{25}$ Metal organic frameworks (MOFs) are prime examples for which carboxylates play a key role in their construction. ${ }^{26}$ It is well recognised that the carboxyl group can bind through several disparate modes when interacting with either a single metal ion or multiple metal sites. ${ }^{27}$ Especially pertinent is the bridging mode for which the two oxygen atoms link together two ions, and help propagate the formation of clusters and higher-order assemblies. Another bridging motif involves bidentate chelation to a single metal ion and a single oxygen interaction with a proximal metal ion. There is no clear-cut method of forcing a specific binding mode to dominate when a superstructure is engineered from all its individual molecular components. Such explicit crystal engineering is still at the infancy stage, but it is clear that the $\mathrm{R}$ group of the carboxyl group must have some effect on controlling packing forces. The chosen $\mathrm{R}$ group for this study was the bulky

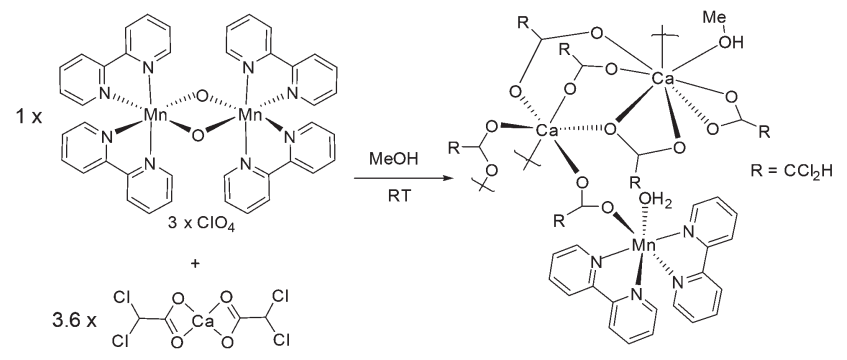

MC

Scheme 1 The room temperature procedure for preparation of the mixed-metal calcium manganese cluster.

dichloromethane subunit, the intention being to manipulate intermolecular interactions.

In an attempt to have partial control of how the manganese centre assembled, the preorganised mixed valence complex, $\left.\left[\mathrm{Mn} \text { (III)(bipy) }{ }_{2} \mathrm{O}_{2} \mathrm{Mn} \text { (Iv)(bipy) }\right)_{2}\right]\left(\mathrm{ClO}_{4}\right)_{3},{ }^{28}$ was targeted as a starting material. To introduce simultaneously the calcium(II) and carboxylate group the complex $\mathrm{Ca}\left(\mathrm{CHCl}_{2} \mathrm{COO}\right)_{2}$ was used. The full synthetic procedure is illustrated in Scheme 1 and represents the optimised conditions for preparation of the supramolecular structure, MC. Thus, mixing of $\left[\mathrm{Mn}(\mathrm{III})(\mathrm{bipy})_{2} \mathrm{O}_{2}\right.$ $\left.\mathrm{Mn}(\mathrm{Iv})(\text { bipy })_{2}\right]\left(\mathrm{ClO}_{4}\right)_{3}$ with $\mathrm{Ca}\left(\mathrm{CHCl}_{2} \mathrm{COO}\right)_{2}$ in $\mathrm{MeOH}$ at room temperature, followed by leaving the solution overnight, resulted in a drastic colour change from dark black to yellow. Upon standing for 24 hours a yellow crystalline material precipitated from the solution. A basic FT-IR of the crystals confirmed the presence of the carboxylate groups (CO stretch $1590 \mathrm{~cm}^{-1}$ and $1390 \mathrm{~cm}^{-1}$ ), and that the $\left[\mathrm{Mn}(\text { bipy })_{2}\right]^{2+}$ was still intact and probably part of the overall complex $(\mathrm{C}-\mathrm{H}$ stretch $3384 \mathrm{~cm}^{-1}$ and $\left.3009 \mathrm{~cm}^{-1}\right)$. It is apparent from the colour change that one or two of the manganese centres had undergone reduction. The $\mathrm{MeOH}$ was presumably the reductant for the reaction.

\section{X-ray crystal structure determination}

Structure of MC. Crystals of the isolated material MC were of suitable quality to collect X-ray diffraction data and to solve the structure. The crystal system is monoclinic and the space group is $P 2_{1} / n$. The basic asymmetric unit structure is shown in Fig. 1, and collected in Table 1 are a selection of pertinent bond lengths. The butterfly-like $\mathrm{Mn}$ (bipy) ${ }_{2}$ group bridges via a carboxyl group to $\mathrm{Ca} 1$ and the vacant coordination site is taken up by a water molecule. The bridging carboxylate between the $\mathrm{Mn}$ and $\mathrm{Ca}$ centres is reminiscent to that observed in the natural WOC cubane cluster. Presumably the water molecule was scavenged from residual water in the $\mathrm{MeOH}$ or is from the original bridging oxide. No isotopic labelling experiments were performed to try and answer the conundrum. From a formal charge count just at the manganese centre, the oxidation state appears to be only $+1 / 2$. In fact, the $\mathrm{Mn}-\mathrm{N}$ bond lengths (Table 1) are typical for a bipy-based complex with a formal oxidation state of manganese(II). Magnetic measurements (see later) were more insightful on this matter. 


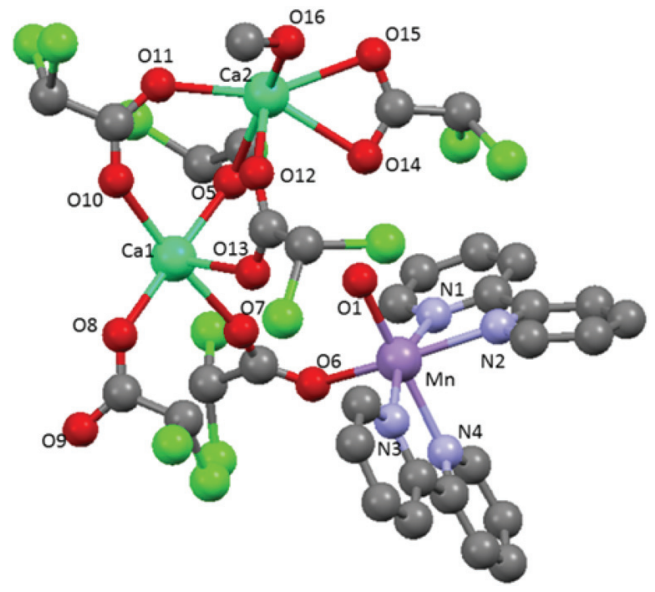

Fig. 1 X-ray determined molecular structure for MC showing the basic asymmetric unit and the $\mathrm{Mn}(\mathrm{Ca})_{2}$ motif. Grey = carbon, red = oxygen, lime green $=$ chlorine, aqua green $=$ calcium, blue $=$ nitrogen, purple $=$ manganese.

Table 1 Selected bond lengths [Å] for MC

\begin{tabular}{llll}
\hline $\mathrm{Mn}-\mathrm{O}(6)$ & $2.147(2)$ & $\mathrm{Mn}-\mathrm{O}(1)$ & $2.119(2)$ \\
$\mathrm{Mn}-\mathrm{N}(4)$ & $2.274(2)$ & $\mathrm{Mn}-\mathrm{N}(2)$ & $2.271(2)$ \\
$\mathrm{Mn}-\mathrm{N}(1)$ & $2.260(2)$ & $\mathrm{Mn}-\mathrm{N}(3)$ & $2.260(2)$ \\
$\mathrm{Ca}(1)-\mathrm{Ca}(2)$ & $4.0877(8)$ & $\mathrm{Ca}(1)-\mathrm{O}(5)$ & $2.292(2)$ \\
$\mathrm{Ca}(1)-\mathrm{O}(7)$ & $2.367(2)$ & $\mathrm{Ca}(1)-\mathrm{O}(8)$ & $2.299(2)$ \\
$\mathrm{Ca}(1)-\mathrm{O}(9 \mathrm{~A})$ & $2.311(2)$ & $\mathrm{Ca}(1)-\mathrm{O}(10)$ & $2.299(2)$ \\
$\mathrm{Ca}(1)-\mathrm{O}(13)$ & $2.365(2)$ & $\mathrm{Ca}(2)-\mathrm{Ca}(2 \mathrm{~B})$ & $3.9621(11)$ \\
$\mathrm{Ca}(2)-\mathrm{O}(16)$ & $2.395(2)$ & $\mathrm{Ca}(2)-\mathrm{O}(4)$ & $2.487(2)$ \\
$\mathrm{Ca}(2)-\mathrm{O}(5)$ & $2.580(2)$ & $\mathrm{Ca}(2)-\mathrm{O}(11)$ & $2.335(2)$ \\
$\mathrm{Ca}(2)-\mathrm{O}(12)$ & $2.333(2)$ & $\mathrm{Ca}(2)-\mathrm{O}(14)$ & $2.537(2)$ \\
$\mathrm{Ca}(2)-\mathrm{O}(15)$ & $2.505(2)$ & $\mathrm{Ca}(2)-\mathrm{O}(15 \mathrm{~B})$ & $2.396(2)$ \\
& & &
\end{tabular}

The Ca1 centre is six coordinate comprising of five $\mu$-carboxylate units, with the final oxygen being part of a $\eta_{2}$-carboxylate coordinated to $\mathrm{Ca} 2$. The $\mathrm{Ca} 2$ centre is 8-coordinate, but as well as containing bridging carboxylate units the ion also binds two $\eta_{2}$-carboxylate subunits. The coordination sphere is completed by a $\mathrm{MeOH}$ molecule. The Ca1-Ca2 distance of $\sim 4.08 \mathrm{~A}$ implies that there is no significant interaction between the two ions. It is noted that the water molecule for $\mathrm{Mn}-\mathrm{OH}_{2}$ is not in close contact with any of the calcium ions, but is instead hydrogen bonded to a $\eta_{2}$-carboxylate group of Ca2. Recalling that the activation of water is often enhanced by secondary bonding interactions such an $\mathrm{H}$-bond, may suggest it has a role in the chemistry of MC. The first coordination sphere of the manganese ion consists of four nitrogen atoms from two bipyridyl ligands, one oxygen atom from a carboxyl group of dichloroacetic acid that bridges $\mathrm{Mn}$ to $\mathrm{Ca}$ and one more vacant coordination site which is taken up by a water molecule (Fig. 1).

The crystal packing diagram is revealing in that the fullybridged calcium(II)-based motif is more clearly seen (Fig. 2A). A chain-like structure with a Ca core is apparent, with $\mathrm{Mn}$ (bipy $)_{2}$ moieties adorning the outer casing. This Ca core is more clearly evident when only the binding groups at the calcium(II) ions are shown (Fig. 2B). The structure comprises a
A
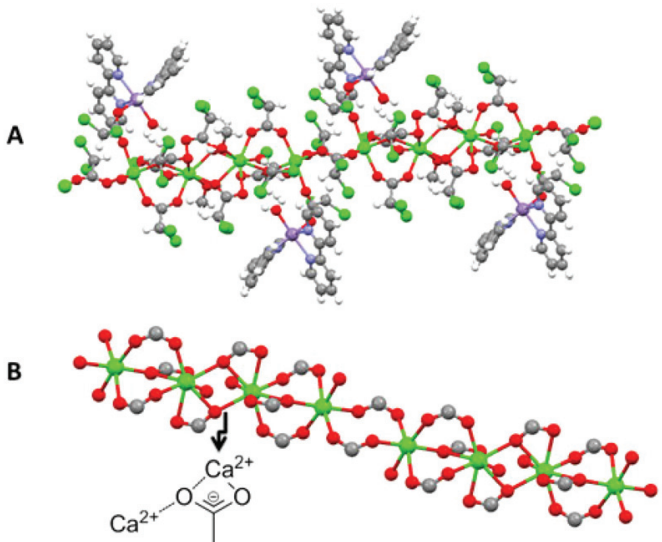

Fig. 2 Partial crystal packing diagram for MC displaying the manganese complexes decorating the calcium(॥)-based chain (A), and the basic structure demonstrating the 6-8-8-6 coordination mode of the calcium(II) ions (B). The insert picture highlights the bridging motif of the carboxyl group. Colours are the same as in Fig. 1.

tetramer of calcium ions running in a coordination number algorithm of 6-8-8-6, with each tetramer linked together by two carboxylate groups. A search of the Cambridge Structural Database found only three similar structures based on a polymerlike calcium(II) ion chain. ${ }^{29-31}$ The apparent charge count around $\mathrm{Ca} 2$ is -3 (two $\eta_{2}$ carboxylates and two $\eta_{1}$ carboxylates), whereas at Ca1 the charge count is $-2 \frac{1}{2}$ (five $\eta_{1}$ carboxylates). The excess charge at the bis-calcium(II) segment is $-1 \frac{1}{2}$, and is clearly the counter charge required for the manganese(II) ion. At a simplistic level the calcium(II) chain-like segment is an extended anion for the periphery manganese complexes. The $\mathrm{Mn}(\text { bipy })_{2}$ subunits are well separated (intra-chain $\mathrm{Mn}-\mathrm{Mn}=$ $15.17 \AA$, inter-chain $\mathrm{Mn}-\mathrm{Mn}=12.31 \AA$ ) in the structure and any interactions between them would expected to be weak. Further crystallographic details are found in the ESI. $\dagger$

\section{Magnetic measurements}

Static magnetic measurements. The equilibrium dc magnetic susceptibility of MC was measured from $1.8 \mathrm{~K}$ to $265 \mathrm{~K}$ with a dc field of $H=1 \mathrm{kOe}$. The thermal dependence can be described with a Curie-Weiss law, $\chi_{\mathrm{dc}}=\chi_{\mathrm{TIP}}+\mathrm{C} /(T-\theta)$, where $\chi_{\mathrm{TIP}}$ is a temperature independent term, $C$ is the Curie constant, and $\theta$ is the Curie temperature which accounts for magnetic interactions (Fig. 3). The obtained values from fit, $\chi_{\mathrm{TIP}}=$ $-0.0018 \pm 0.0003 \mathrm{emu} \mathrm{mol}^{-1}, C=4.463 \pm 0.007 \mathrm{emu} \mathrm{K} \mathrm{mol}{ }^{-1}$ and $\theta=-0.033 \pm 0.003 \mathrm{~K}$ agree with expected values for a $\mathrm{Mn}^{2+} \mathrm{d}^{5}$ ion. ${ }^{32}$ Indeed, the expected Curie constant $\left(C_{\mathrm{th}}\right)$ for a $\mathrm{Mn}^{2+}$ ion, with $L=0, S=5 / 2$ isotropic spin and a gyromagnetic factor $g=2.0$, is $=4.375 \mathrm{emu} \mathrm{K} \mathrm{mol}^{-1}$ and is in very good agreement with experimental results. No deviations from Curie law behaviour are observed down to $1.8 \mathrm{~K}$ (inset Fig. 3). The obtained value of the Curie temperature would suggest that possible anti-ferromagnetic interactions between separate $\mathrm{Mn}^{2+}$ ions are almost negligible.

The isothermal $M(H)$ curves, measured at $T=1.8 \mathrm{~K}, 2.5 \mathrm{~K}$, $3.5 \mathrm{~K}$ and $5.0 \mathrm{~K}$ show a saturation trend as a function of 


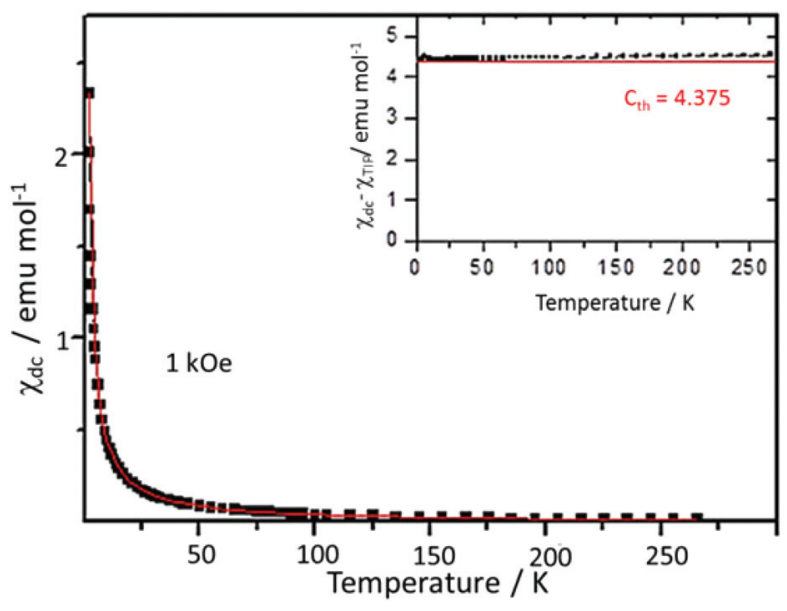

Fig. 3 Temperature dependence of the dc magnetic susceptibility of MC (black squares). Experimental data measured in an applied field $H=$ $1 \mathrm{kOe}$. Fit to a Curie-Weiss law is shown in red. Inset: temperature dependence of the product $\left(\chi_{\mathrm{dc}}-\chi_{\mathrm{TIP}}\right) T$; in red, $C_{\mathrm{th}}$, expected $C$ value for $\mathrm{Mn}($ II).

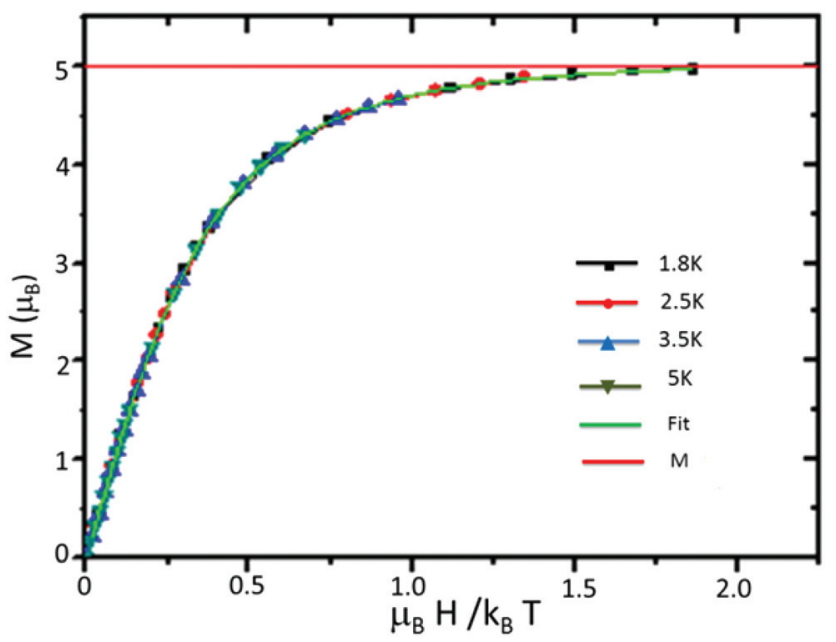

Fig. 4 The magnetisation per formula unit, in Bohr magnetons, as a function of the reduced magnetic field, $\mu_{\mathrm{B}} H / k_{\mathrm{B}} T$.

magnetic field, $H$. The magnetisation per formula unit, in Bohr magnetons $\left(\mu_{\mathrm{B}}\right)$, as a function of the reduced magnetic field, $\mu_{\mathrm{B}} H / k_{\mathrm{B}} T$, where $k_{\mathrm{B}}$ is the Boltzmann constant, is given in Fig. 4. It is observed that all the curves collapse to a universal curve. The saturation magnetization amounts to $5 \mu_{\mathrm{B}}$ f.u. $^{-1}$ for one $\mathrm{Mn}^{2+}$ ion per formula unit. In the case of non-interacting paramagnetic entities and assuming an isotropic $\mathrm{g}$ factor, such a dependency is described by eqn (1):

$$
M\left(\mu_{\mathrm{B}}\right)=g S B_{S}\left(g S \frac{\mu_{\mathrm{B}} H}{k_{\mathrm{B}} T}\right)
$$

where $B_{S}$ is the Brillouin function. Isothermal curves can be fitted to above function for $S=5 / 2$ and isotropic $g_{J}=1.991 \pm$ 0.001 .
Therefore, down to $1.8 \mathrm{~K}$, an oxidation state of $\mathrm{Mn}^{2+}$ is observed. For this ion, zero field splitting are usually small, of the order of $10^{-2} \mathrm{~cm}^{-1}$, and so a $S=5 / 2 \mathrm{~g}=2$ isotropic state is normally observed. Moreover, no contribution from the $\mathrm{Mn}$ (II) magnetic interaction down to $1.8 \mathrm{~K}$ can be distinguished.

Dynamic magnetic measurements. In order to perform a more complete picture of the magnetic behaviour for MC, ac susceptibility measurements in the frequency range $0.1<f<$ $2000 \mathrm{~Hz}$ were performed as a function of field strength (0-4 kOe) and temperature (1.8-4.6 K). At $H=0$ no slow relaxation behaviour is observed. However, under the application of field two different relaxational pathways become accessible, as apparent from the double peaked $\chi^{\prime \prime}(f)$ data shown in Fig. 5a and $\mathrm{b}$. From these data the relaxation time, $\tau$, at different temperatures and fields is obtained since $\chi^{\prime \prime}(f)$ has a maximum when the condition $2 \pi f \tau=1$ is fulfilled (Fig. $5 \mathrm{c}$ and d). The intensity of the $\chi^{\prime \prime}$ peak corresponding to the high frequency relaxation process, with relaxation time $\tau_{\mathrm{hf}}$, is much higher than that of the slow process, $\tau_{\mathrm{D}}$, which gains intensity with the field. Fig. $5 \mathrm{c}$ shows the dependence of the two relaxation times with $1 / T$, determined from the $\chi^{\prime \prime}(f, T)$ data at the field $H=1.5 \mathrm{kOe}$ and optimising the $\tau_{\mathrm{hf}}$ peak. The first relaxational process $\tau_{\mathrm{D}} \sim 0.1 \mathrm{~s}$, is almost temperature independent, whereas the second one $\tau_{\mathrm{hf}} \sim 1-8 \times 10^{-4} \mathrm{~s}$, exhibits a $\ln \tau(1 / T)$ dependence with a slope of $\sim 5.05 \mathrm{~K}$ at low $T$. The order of magnitude of $\tau_{\mathrm{D}}$ and its field and temperature behaviour suggests this relaxation process may correspond to the ubiquitous direct process reported in many SIMs. ${ }^{33}$ The other $\tau_{\mathrm{hf}}$ process cannot be ascribed to an Orbach process, since the energy calculated from the $\tau_{\mathrm{hf}}(1 / T)$ plot of $5.05 \mathrm{~K}$, is larger than the Zeeman splitting between levels at $1.5 \mathrm{kOe}$; the $\Delta_{\text {Zee }}=g_{\mu_{\mathrm{B}}} H S=$ $1.02 \mathrm{~K}$ and the anisotropy energy for $\mathrm{Mn}$ is expected to be very small. Alternatively, the process can be explained in terms of the resonant phonon trapping (RPT) mechanism, ${ }^{34,35}$ taking place when the phonon-bottleneck (PB) effect sets in. This is not unreasonable since the observed $\tau_{\mathrm{hf}}{ }^{-1}(T)=K T^{2.4}$ temperature dependence (inset Fig. 5c) is close to the $\tau_{\mathrm{hf}}{ }^{-1} \propto T^{2}$ law theoretically expected for this type of process. ${ }^{36}$ The slight deviation in the exponent value indicates that in the studied range of temperatures and fields, the MC does not represent a perfect two-level system. ${ }^{37}$ The slow relaxation through RPT has been previously reported in isotropic $(L=0) \mathrm{Gd}(\mathrm{III})^{37,38}$ complexes but, to our knowledge, never in Mn examples.

Mass spectrometry analysis. In solution we might expect the extended structure for MC to disassemble into smaller oligomeric fragments. An electrospray mass spectrum for the complex dissolved in $\mathrm{MeOH}$ was collected in attempt to identify possible ions. The low mass region contains molecular ions that appear to incorporate the calcium(II) and manganese(II) ions and the 2,2-dichloroacetate ligand. At higher mass the spectrum is dominated by several clusters of ion peaks (Fig. 6) that appear to contain the basic $\left[\mathrm{Mn}(\text { bipy })_{2}\right]^{2+}$ ion. Collected in Table 2 are a series of prospective molecular ions and their masses, noting that water and methanol adducts are feasible. Several ions are identified which support structures where the carboxylate ligand and calcium(II) ion(s) are associated with 

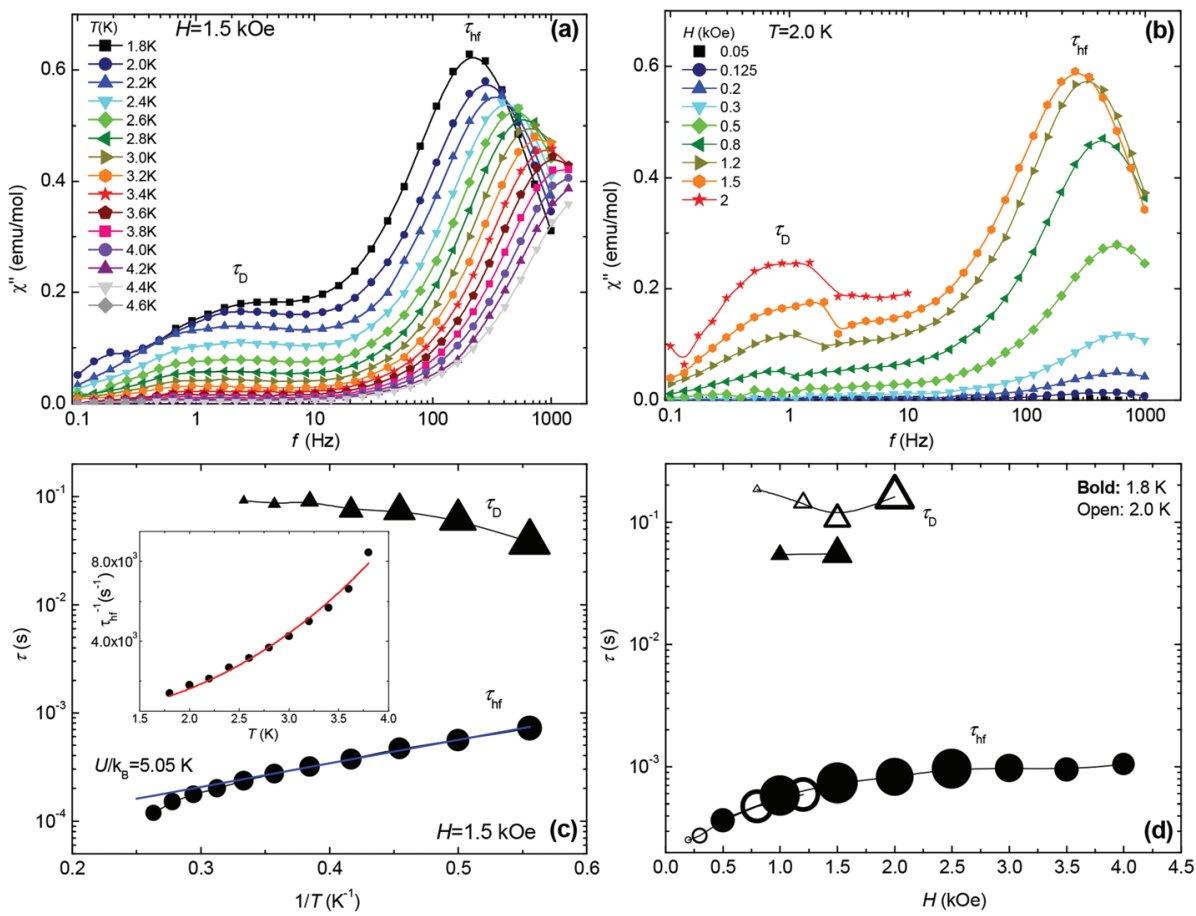

Fig. 5 Top panels: Imaginary component of the ac susceptibility as a function of frequency, (a) at different temperatures, constant field $H=$ $1.5 \mathrm{kOe}$; (b) at different fields, constant temperature $T=2.0 \mathrm{~K}$. Bottom panels: (c) relaxation times of the two observed processes as a function of $1 / T$ at $1.5 \mathrm{kOe}$, and Inset: $\tau_{\mathrm{hf}}{ }^{-1} \mathrm{vs}$. temperature data and fit to the function $\tau_{\mathrm{hf}}{ }^{-1}=K T 2.4\left(K=292 \mathrm{~s}^{-1} \mathrm{~K}^{-2}\right)$; (d) field-dependence of the two relaxation times at $1.8 \mathrm{~K}$ and $2.0 \mathrm{~K}$. The size of the symbols is proportional to the $\chi^{\prime \prime}$ peak intensity.

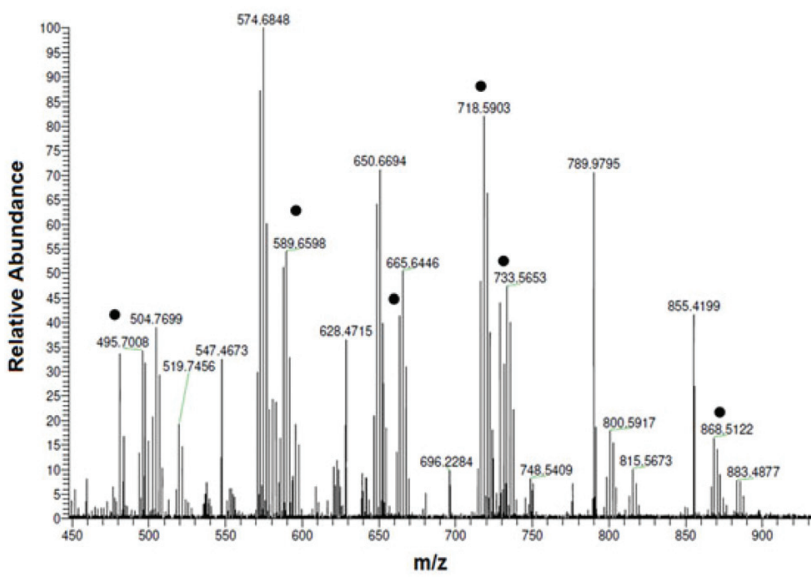

Fig. 6 Selected region of the electrospray mass spectrum for MC collected in $\mathrm{MeOH}$.

the manganese centre. The mass spectrometry results would support the hypothesis that in a donor organic solvent calcium-manganese clusters are still intact.

UV-visible spectroscopy. The yellow crystals for MC were readily soluble in deionised water $(\mathrm{pH} \sim 6)$, and the electronic spectrum is shown in Fig. 7. It is likely, as evidenced by ESI mass spectrometry, that the crystal superstructure is disassembled when dissolved in water to produce the basic dimers. Two main electronic absorption bands are observed at $280 \mathrm{~nm}$ and $233 \mathrm{~nm}$ with the latter being slightly less intense.
The molar absorption coefficients $\left(\varepsilon_{\max }\right)$ for these two bands are appreciably large and so are assigned primarily to $\pi-\pi^{*}$ transitions associated with the $2,2^{\prime}$-bipyridine ligand. There is an evident tail in the absorption profile from around $300 \mathrm{~nm}$ which can be more readily seen in the insert of Fig. 7. We discount this tail is because of Rayleigh scattering from nano-particulates in solution owing to a poor fit to a $1 / \lambda^{4}$ dependency. Considering that Laporte forbidden $\mathrm{d}-\mathrm{d}$ electronic transitions for the $\mathrm{d}^{5} \mathrm{Mn}^{2+}$ ion are likely too weak to be observed, the lowenergy profile is assigned to the tail of a metal-to-ligand charge transfer (MLCT) transition.

Electrochemistry. There are several reports, particularly by Sawyer et al., ${ }^{39}$ describing the electrochemical behaviour of manganese complexes of the type $\left[\mathrm{Mn}(\text { bipy })_{3}\right]^{2+}$, but less literature material covers the redox response for $\left[\mathrm{Mn}(\mathrm{bipy})_{2} \mathrm{X}_{2}\right]^{n+}$ where $\mathrm{X}$ represents a spectator or solvent ligand. ${ }^{40}$ As a starting point for comparison purposes we investigated the cyclic voltammetry for $\left[\mathrm{Mn}(\text { bipy })_{2} \mathrm{Cl}_{2}\right]$ and $\mathrm{MC}$ in buffered $\mathrm{H}_{2} \mathrm{O}$ containing $0.2 \mathrm{M} \mathrm{KCl}(\mathrm{pH}$ 4) at a glassy carbon working electrode (Fig. 8). The positive potential window was relatively uneventful with no real sign of oxidation of the manganese centre in the two complexes. The only point to note is the small reduction wave observed at around $+0.4 \mathrm{~V} \mathrm{vs.} \mathrm{Ag} / \mathrm{AgCl}$ which is absent if the potential is not swept above $1 \mathrm{~V}$. This wave is presumably associated with the di- $\mu$-oxo-dimanganese(III,IV or IV,IV) species which is known to be produced following oxidation of manganese(II) polyimine complexes. Holding the potential at $+1.3 \mathrm{~V}$ for several minutes resulted in an increase in size of the 
Table 2 Feasible molecular species from dissolution of $\mathrm{MC}$ in $\mathrm{MeOH}$ as determined by electrospray mass spectrometry

\begin{tabular}{|c|c|}
\hline Molecular ion species & Mass \\
\hline \multirow[t]{4}{*}{$\left[\mathrm{Mn}(\text { bipy })_{2}\right]^{2+} \mathrm{L}^{+}+\left(\mathrm{H}_{2} \mathrm{O}\right)_{n}+(\mathrm{MeOH})_{n}$} & 494 \\
\hline & $512(n=1), 530(n=2)$ \\
\hline & $526(n=1), 558(n=2)$ \\
\hline & $590(n=3)$ \\
\hline $\multirow{4}{*}{\left[\mathrm{Mn}(\text { bipy })_{2}\right]^{2+} \mathrm{LCa}^{2+}}^{3+}+\left(\mathrm{H}_{2} \mathrm{O}\right)_{n}\left(-2 \mathrm{H}^{+}\right)^{b}+(\mathrm{MeOH})_{n}\left(-2 \mathrm{H}^{+}\right)^{b}$ & $534(532)^{a}$ \\
\hline & $550(n=1), 568(n=2)$ \\
\hline & $564(n=1), 596(n=2)$ \\
\hline & $628(n=3)$ \\
\hline $\multirow[t]{3}{*}{\left[\mathrm{Mn}(\mathrm{bipy})_{2}\right]^{2+} \mathrm{L}\left(\mathrm{Ca}^{2+}\right)_{2}}^{5+}+\left(\mathrm{H}_{2} \mathrm{O}\right)_{n}\left(-4 \mathrm{H}^{+}\right)^{b}+(\mathrm{MeOH})_{n}\left(-4 \mathrm{H}^{+}\right)^{b}$ & $574(570)^{a}$ \\
\hline & $588(n=1), 606(n=2)$ \\
\hline & $600(n=1), 632(n=2)$ \\
\hline $\multirow{4}{*}{\left[\mathrm{Mn}(\text { bipy })_{2}\right]^{2+}(\mathrm{L})_{2} \mathrm{Ca}^{2+}}^{2+}+\left(\mathrm{H}_{2} \mathrm{O}\right)_{n}\left(-\mathrm{H}^{+}\right)^{b}+(\mathrm{MeOH})_{n}\left(-\mathrm{H}^{+}\right)^{b}$ & $\begin{array}{l}664(n=3) \\
663(662)^{a}\end{array}$ \\
\hline & $680(n=1), 698(n=2)$ \\
\hline & $694(n=1), 726(n=2)$ \\
\hline & $758(n=3)$ \\
\hline $\multirow[t]{4}{*}{\left[\mathrm{Mn}(\text { bipy })_{2}\right]^{2+}(\mathrm{L})_{2}\left(\mathrm{Ca}^{2+}\right)_{2}}^{4+}+\left(\mathrm{H}_{2} \mathrm{O}\right)_{n}\left(-3 \mathrm{H}^{+}\right)^{b}+(\mathrm{MeOH})_{n}\left(-3 \mathrm{H}^{+}\right)^{b}$ & $703(700)^{a}$ \\
\hline & $718(n=1), 736(n=2)$ \\
\hline & $732(n=1), 764(n=2)$ \\
\hline & $796(n=3)$ \\
\hline $\multirow{3}{*}{\left[\mathrm{Mn}(\text { bipy })_{2}\right]^{2+}(\mathrm{L})_{3}\left(\mathrm{Ca}^{2+}\right)_{2}}^{3+}+\left(\mathrm{H}_{2} \mathrm{O}\right)_{n}\left(-2 \mathrm{H}^{+}\right)^{b}+(\mathrm{MeOH})_{n}\left(-2 \mathrm{H}^{+}\right)^{b}$ & $816(814)^{a}$ \\
\hline & $832(n=1), 850(n=2), 868(n=3)$ \\
\hline & $\begin{array}{l}846(n=1), 878(n=2) \\
910(n=3)\end{array}$ \\
\hline
\end{tabular}

$\mathrm{L}=2$,2-dichloroacetate, bipy $=2,2^{\prime}$-bipyridine. ${ }^{a}$ Mass of singly positively charged ion by proton loss. ${ }^{b}$ Protons removed to obtain singly positively charged ion.

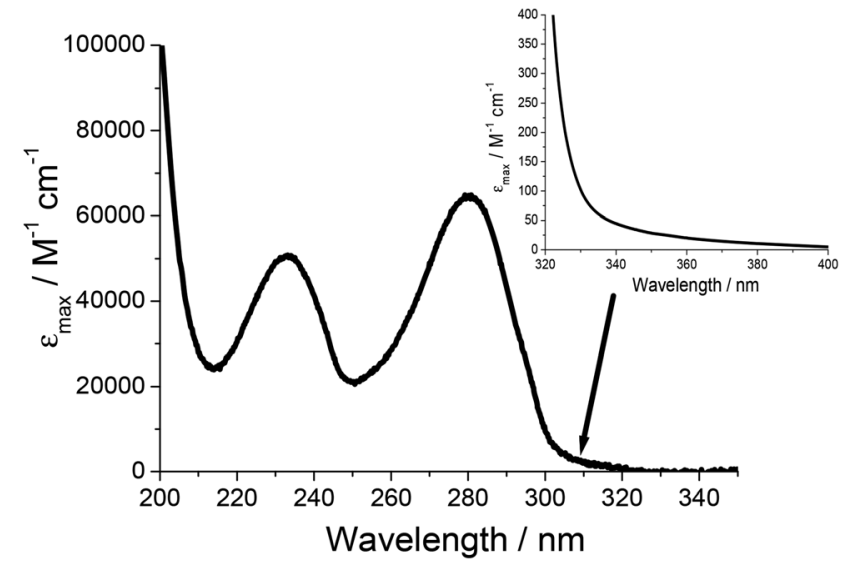

Fig. 7 Room temperature UV-visible spectrum for $M C$ in deionised water $(\mathrm{pH} \sim 6)$. Insert shows an expansion of the region shown by the arrow.

wave as more dimer was produced. The scanning to highly reducing potentials revealed for both complexes two closelyspaced peaks at $-1.47 \mathrm{~V}$ and $-1.55 \mathrm{~V}$ vs. Ag/AgCl. Two clear reverse oxidation waves are seen at $-1.18 \mathrm{~V}$ and $-0.97 \mathrm{~V}$ for $\left[\mathrm{Mn}(\text { bipy })_{2} \mathrm{Cl}_{2}\right]$ and $-1.16 \mathrm{~V}$ and -0.99 for $\mathrm{MC} v s$. $\mathrm{Ag} / \mathrm{AgCl}$. The reverse parts of the waves are clearly located at less negative potentials than expected if the redox process was fully reversible. Full reversibility is not produced at $\mathrm{pH} 7$ or 10 , but at the latter $\mathrm{pH}$ the peak separation is $290 \mathrm{mV}$ and $i_{\mathrm{pc}} / i_{\mathrm{pa}}=1.4$. Addition of an electron to either complex is ligand-based and it appears that protonation of ligand-based radical anion is partial cause for the electrochemical irreversibility.

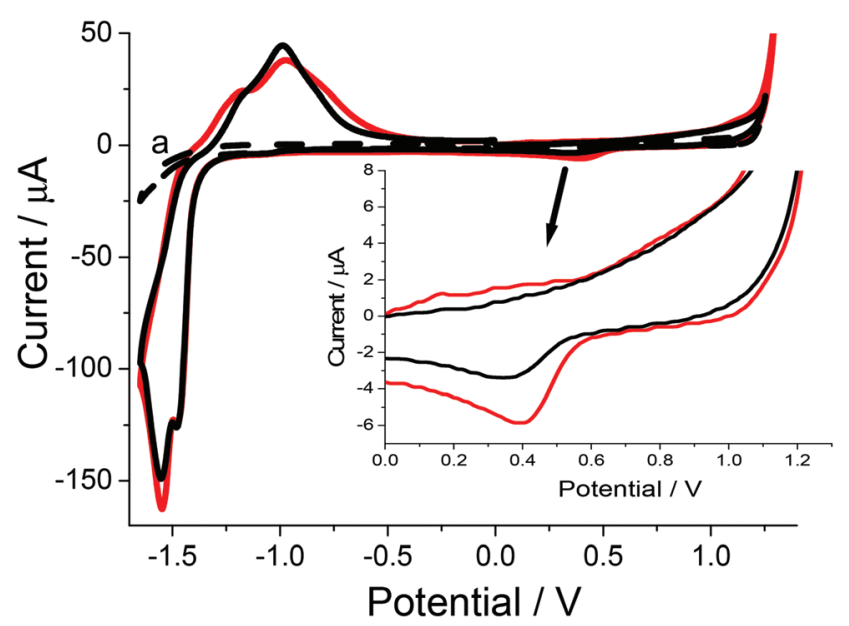

Fig. 8 Cyclic voltammograms for $\left[\mathrm{Mn}(\text { bipy })_{2} \mathrm{Cl}_{2}\right]$ (red) and $\mathrm{MC}$ (black) in distilled $\mathrm{H}_{2} \mathrm{O}$ containing $0.2 \mathrm{M} \mathrm{KCl}(\mathrm{pH} 4)$ at a glassy carbon electrode (scan rate $=50 \mathrm{mV} \mathrm{s}^{-1}$, reference $=\mathrm{Ag} / \mathrm{AgCl}$ ). Insert shows an expansion after cycling to $1.3 \mathrm{~V}$. a = background electrolyte scan.

The redox chemistry of MC in dry MeCN at positive potentials is more resolved than the aqueous case and contains at least two waves in the forward sweep (Fig. 9). For comparison purposes a cyclic voltammogram for $\left[\mathrm{Mn}(\mathrm{II})(\mathrm{bipy})_{2} \mathrm{Cl}_{2}\right]$ under near identical conditions is also presented. Clearly the onset of oxidation for MC (region a insert) occurs at lower potential than the simple $\left[\mathrm{Mn}(\mathrm{II})(\mathrm{bipy})_{2} \mathrm{Cl}_{2}\right]$ case. The second wave associated with MC ( $\mathrm{b}$ and $\mathrm{c}$ insert) is quasi-reversible $\left(E_{1 / 2}=\right.$ $+0.85 \mathrm{~V}, \Delta E=80 \mathrm{mV} v s . \mathrm{Fc}^{+} / \mathrm{Fc}$ ) and is comparable to that seen for the control complex. It should be noted that $E_{1 / 2}=+0.90 \mathrm{~V}$ 


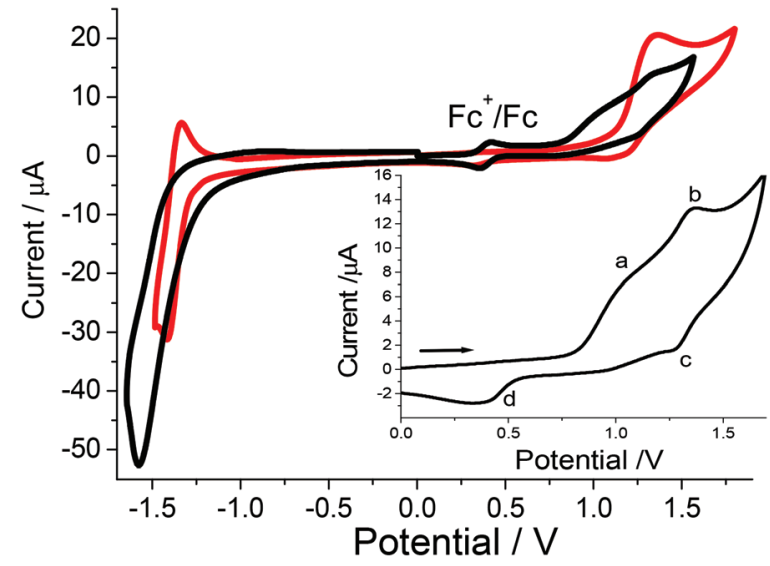

Fig. 9 Cyclic voltammogram for $\mathrm{MC}$ (black) and $\left[\mathrm{Mn}(\Perp)(\text { bipy })_{2} \mathrm{Cl}_{2}\right]$ (red) in dry MeCN containing 0.2 M TBATFB against a silver wire and using ferrocene as the internal standard. Insert shows a positive potential only wave containing no ferrocene for $\mathrm{MC}$. Scan rate $=50 \mathrm{mV} \mathrm{s}^{-1}$, working electrode $=$ glassy carbon .

vs. $\mathrm{Fc}^{+} / \mathrm{Fc}$ for $\left[\mathrm{Mn}(\text { bipy })_{3}\right]^{2+}$ measured under the same conditions, and is associated with the reversible $\mathrm{Mn}$ (II)/Mn(III) couple. There is again indication that the dimer complex is formed (d insert) after cycling to high oxidation potential. In the negative potential scan segment of the cyclic voltammogram an irreversible ligand-based reduction is seen at $-1.92 \mathrm{~V}$ vs. $\mathrm{Fc}^{+} / \mathrm{Fc}$. This wave is shifted to a more negative potential by $c a .150 \mathrm{mV}$ when compared to $\left[\mathrm{Mn}(\mathrm{II})(\mathrm{bipy})_{2} \mathrm{Cl}_{2}\right]$ and $\left[\mathrm{Mn}(\mathrm{bipy})_{3}\right]^{2+}$. There is a clear effect on the metal-centred and ligand-based redox chemistry by the presence of the proximal calcium(II) entity in the complex of MC. Reduction of formal charge at the manganese(II) ion coupled with electron density build-up at the bipy sites would account for the observed redox perturbations. There are several reports on the how redox-inactive metal ions modulate the reduction potentials of heterometallic manganese-oxido clusters. Recent work by Agapie et $a l .{ }^{41}$ found that potential shifts were related to the metal ion Lewis acid strength. The Lewis acid was directly associated with the oxido ligand in the manganese cluster, and as electron density was removed from the cluster its reduction became more facile. The converse is the initial oxidation of the lower oxidation state manganese centres must be more difficult. For MC the calcium(II) ion is not directly associated with the manganese(II) centre, and a Lewis acid strength argument does not appear to be valid. From the X-ray structure for MC there was the reasoning that the manganese centre was less positive than the expected formal +2 charge; magnetic measurements do not support such an idea since all behaviour is consistent with a $\mathrm{Mn}^{2+}$ ion. Solution species are by their nature more dynamic and it is feasible that the cyclic voltammogram is representative of a structure that is not typical of the solid state. It is worth recalling that the "charging up" of the $\mathrm{Mn}_{4} \mathrm{Ca}$ cluster in PSII is photochemically driven (Kok model) starting with three manganese(III) ions and a manganese(Iv) ion. The highly oxidising $\mathrm{P}_{680^{+}}$can readily drive via the redox-active tyrosine the reaction to create the redox equivalent to oxidise water; the thermodynamic ease of charging up the cluster is not that important. Here we seem to be observing a $\mathrm{Ca}^{2+}$ ion effect which is facilitating the oxidation of the manganese ion.

\section{Conclusions}

By way of a self-assembly process it is straightforward to prepare a calcium(II) carboxylate chain decorated at precise locations with the butterfly-like $\mathrm{Mn}(\text { bipy })_{2}$ units. It is evident that the molecular system is not structurally related to the $\mathrm{Mn}_{4} \mathrm{CaO}_{5}$ WOC catalyst found in Photosystem II, but opens a possible different design route to WOC catalysts not based entirely on the cubane cluster. It is conceivable to imagine decorating around a calcium chain structure, manganese ring-like motifs to form a rod-axle (rotaxane-like) array containing preorganised water channels. We plan to explore this idea by the modification of carboxylate units used in the synthesis and the manganese precursor complexes. In addition, it has been shown that $\mathrm{Mn}(\mathrm{bipy})_{2}$ on the calcium(II) chain behaves as a Single-Ion Magnet, showing field-induced slow magnetic relaxation via two different pathways. This is the first example of a mononuclear manganese(II) complex exhibiting SIM behaviour.

\section{Experimental}

All chemicals were purchased from commercial sources and used as received unless otherwise stated. The calcium(II) salt of dichloroacetic acid (DCA) was prepared by the reaction between $\mathrm{CaCO}_{3}$ and dichloroacetic acid in a ratio $1: 2$. The complex $\left[\mathrm{Mn}_{2} \mathrm{O}_{2}(\text { bipy })_{4}\right]\left(\mathrm{ClO}_{4}\right)_{3}$ was prepared according to the literature. ${ }^{28}$ IR data (solid sample): 3384, 3009, 1590, 1541, 1472, 1439, 1390, 1221, 1157, 1102, 1016, 960, 826, 761, 700, $646 \mathrm{~cm}^{-1}$.

Cyclic voltammetry experiments were performed using a fully automated $\mathrm{HCH}$ Instruments Electrochemical Analyzer and a three-electrode set-up consisting of a glassy carbon working electrode, a platinum wire counter electrode and an $\mathrm{Ag} / \mathrm{AgCl}$ reference electrode. Cyclic voltammograms were collected in either deoxygenated MeCN containing tetrabutylammonium tetrafluoroborate $\left(\begin{array}{lll}0.2 & \mathrm{M}\end{array}\right)$ as background electrolyte, or in deionised water containing $\mathrm{KCl}(0.2 \mathrm{M})$. Oxidation potentials were reproducible to within $\pm 15 \mathrm{mV}$.

Variable temperature magnetic susceptibility and magnetization measurements were performed using a Quantum Design SQUID-Based Magnetometer MPMS-XL5. Data were collected on polycrystalline samples in the $1.8-260 \mathrm{~K}$ range. Isothermal magnetization curves were obtained at $1.8 \mathrm{~K}, 2.5 \mathrm{~K}$, $3.5 \mathrm{~K}$ and $5 \mathrm{~K}$ in the range of $0 \mathrm{~T} \leq \mu_{0} H \leq 5 \mathrm{~T}$. Measurements on powdered samples were performed with the addition of Daphne oil, introduced to fix the grains at low temperatures.

\section{Preparation of $\left[\mathrm{Mn}(\text { bipy })_{2} \mathrm{Ca}_{2}(\mathrm{DCA})_{\mathbf{6}}\left(\mathrm{H}_{2} \mathrm{O}\right)\left(\mathrm{CH}_{3} \mathrm{OH}\right)\right](\mathrm{MC})$}

$\left[\mathrm{Mn}_{2} \mathrm{O}_{2}(\text { bipy })_{4}\right]\left(\mathrm{ClO}_{4}\right)_{3}(0.3 \mathrm{~g}, 0.28 \mathrm{mmol})$ and $\mathrm{Ca}\left(\mathrm{CHCl}_{2} \mathrm{COO}\right)_{2}$ $(0.3 \mathrm{~g}, 1 \mathrm{mmol})$ were mixed in $\mathrm{CH}_{3} \mathrm{OH}(10 \mathrm{ml})$. The reaction 
was stirred overnight to afford a yellow solution. After filtration the solution was allowed to stand undisturbed for $24 \mathrm{~h}$, and the resulting large block yellow crystals were collected by filtration. IR data: 3384, 3009, 1590, 1541, 1472, 1439, 1390, $1221,1157,1102,1016,960,826,761,700,646 \mathrm{~cm}^{-1}$. Elemental analysis calc. for $\mathrm{C}_{33} \mathrm{H}_{28} \mathrm{Ca}_{2} \mathrm{Cl}_{12} \mathrm{MnN}_{4} \mathrm{O}_{14}: \mathrm{C}, 31.33 \% ; \mathrm{H}$, $2.23 \%$; N, 4.43\%. Found: C, 31.12\%; H, 2.21\%; N, 4.38\%.

\section{Acknowledgements}

This work was mainly funded by the FP7-PEOPLE-2009-IRSES Nr. 246902 grant, and partially funded by the Spanish MINECO project MAT11/23791 and the DGA project E34 (cofunded by the Fondo Social Europeo) and the European Union FEDER. Authors would like to acknowledge the use of Servicio General de Apoyo a la Investigación-SAI, University of Zaragoza. The EPSRC sponsored Mass Spectrometry Service at Swansea is thanked for collecting mass spectra.

\section{Notes and references}

1 R. H. Holm, P. Kennepohl and E. I. Solomon, Chem. Rev., 1996, 96, 2239; C. Andreini, I. Bertini, G. Cavallaro, G. L. Holliday and J. M. Thornton, J. Biol. Inorg. Chem., 2008, 13, 1205.

2 D. J. Evans and C. J. Pickett, Chem. Soc. Rev., 2003, 32, 268; P. K. Mascharak, Coord. Chem. Rev., 2002, 225, 201; R. Kramer, Coord. Chem. Rev., 1999, 182, 243.

3 B. W. Matthews, Acc. Chem. Res., 1988, 21, 333; S. M. Fabiane, M. K. Sohi, T. Wan, D. J. Payne, J. H. Bateson, T. Mitchell and B. J. Sutton, Biochemistry, 1998, 37, 12404.

4 Md. I. Hassana, B. Shajee, A. Waheed, F. Ahmada and W. S. Sly, Bioorg. Med. Chem., 2013, 21, 1570; J. P. Colman, J. Biol. Chem., 1967, 242, 5212; S. Lindskog and J. E. Colman, Proc. Natl. Acad. Sci. U. S. A., 1973, 70, 2505.

5 J. V. Bannister, W. H. Bannister and G. Rotilio, Crit. Rev. Biochem., 1987, 22, 111.

6 D. P. Riley, Chem. Rev., 1999, 99, 2573.

7 J. A. L. da Silva, J. J. F. da Silva and A. J. L. Pombeiro, Coord. Chem. Rev., 2013, 257, 2388; T. L. Poulos, Arch. Biochem. Biophys., 2010, 500, 3; H.-P. Hersleth, U. Ryde, P. Rydberg, C. H. Görbitz and K. K. Andersson, J. Inorg. Biochem., 2006, 100, 460.

8 M. Costas, K. Chen and L. Que Jr., Coord. Chem. Rev., 2000, 200-202, 517; G. Smulevich, C. Jakopitsch, E. Droghetti and C. Obinger, J. Inorg. Biochem., 2006, 100, 568.

9 L. Rulíŝek and U. Ryde, Coord. Chem. Rev., 2013, 257, 445.

10 P. He and G. R. Moran, J. Inorg. Biochem., 2011, 105, 1259; N. R. Rose, M. A. McDonough, O. N. F. King, A. Kawamura and C. J. Schofield, Chem. Soc. Rev., 2011, 40, 4364.

11 (a) T. L. Poulos, Chem. Rev., 2014, 114, 3919; (b) D. D. Ulmer and B. L. Vallee, Adv. Chem., 1971, 10, 187.
12 A. Guskov, A. Gabdulkhakov, M. Broser, C. Glöckner, J. Hellmich, J. Kern, J. Frank, F. Müh, W. Saenger and A. Zouni, ChemPhysChem, 2010, 11, 1160.

13 K. N. Ferreira, T. M. Iverson, K. Maghlaoui, J. Barber and S. Iwata, Science, 2004, 303, 1831.

14 Y. Umena, K. Kawakami, J.-R. Shen and N. Kamiya, Nature, 2011, 473, 55.

15 J. P. McEvoy, J. A. Gascon, V. S. Batista and G. W. Brudvig, Photochem. Photobiol. Sci., 2005, 4, 940; J. Dasgupta, G. M. Ananyev and G. C. Dismukes, Coord. Chem. Rev., 2008, 252, 347; G. M. Ananyev, L. Zaltsman, C. Vasko and G. C. Dismukes, Biochim. Biophys. Acta, 2001, 1503, 52.

16 Y. J. Park, J. W. Ziller and A. S. Borovik, J. Am. Chem. Soc., 2011, 133, 9258; D. Shevela, S. Koroidov, M. M. Najafpour, J. Messinger and P. Kurz, Chem. - Eur. J., 2011, 17, 5415; M. M. Najafpour, T. Ehrenberg, M. Wiechen and P. Kurz, Angew. Chem., Int. Ed., 2010, 49, 2233; I. J. Hewitt, J.-K. Tang, N. T. Madhu, R. Clérac, G. Buth, C. E. Anson and A. K. Powell, Chem. Commun., 2006, 2650; C. P. Horwitz, J. T. Warden and S. T. Weintraub, Inorg. Chim. Acta, 1996, 246, 311; S. M. Gorun, R. T. Stibrany and A. Lill, Inorg. Chem., 1998, 37, 836; I. Gil de Muro, M. Insausti, L. Lezama, M. K. Urtiaga, M. I. Arriortua and T. Rojo, Dalton Trans., 2000, 3360.

17 A. Mishra, W. Wernsdorfer, K. A. Abboud and G. Christou, Chem. Commun., 2005, 54; A. Mishra, J. Yano, Y. Pushkar, V. K. Yachandra, K. A. Abboud and G. Christou, Chem. Commun., 2007, 1538.

18 V. Kotzabasaki, R. Inglis, M. Siczek, T. Lis, E. K. Brechin and C. J. Milios, Dalton Trans., 2011, 40, 1693.

19 E. Y. Tsui, J. S. Kanady and T. Agapie, Inorg. Chem., 2013, 52, 13833.

20 R. Sessoli, D. Gatteschi, A. Caneschi and M. A. Novak, Nature, 1993, 365, 141; J. R. Friedman, M. P. Sarachik, J. Tejada and R. Ziolo, Phys. Rev. Lett., 1996, 76, 3830; G. E. Kostakis, A. M. Ako and A. K. Powell, Chem. Soc. Rev., 2010, 39, 2238.

21 A. J. Tasiopoulos, A. Vinslava, W. Wernsdorfer, K. A. Abboud and G. Christou, Angew. Chem., Int. Ed., 2004, 43, 2117; Q. Wu, Y.-G. Li, Y. H. Wang, R. Clérac, Y. Lu and E.-B. Wang, Chem. Commun., 2009, 5743; O. Roubeau and R. Clérac, Eur. J. Inorg. Chem., 2008, 4325.

22 R. Ishikawa, R. Miyamoto, H. Nojiri, B. K. Breedlove and M. Yamashita, Inorg. Chem., 2013, 52, 8300.

23 J. Vallejo, A. Pascual-lvarez, J. Cano, I. Castro, M. Julve, F. Lloret, J. Krzystek, G. De Munno, D. Armentano, W. Wernsdorfer, R. Ruiz-García and E. Pardo, Angew. Chem., Int. Ed., 2013, 125, 14325.

24 A. Grigoropoulos, M. Pissas, P. Papatolis, V. Psycharis, P. Kyritsis and Y. Sanakis, Inorg. Chem., 2013, 52, 12869.

25 B. H. He, M. L. Tong and X. M. Chen, Coord. Chem. Rev., 2005, 249, 545.

26 A. J. Fletcher, K. M. Thomas and M. J. Rosseinsky, J. Solid State Chem., 2005, 178, 2491; S. Qui and G. Zhu, Coord. 
Chem. Rev., 2009, 253, 2891; S. T. Meek, J. A. Greathouse and M. D. Allendorf, Adv. Mater., 2011, 23, 249.

27 F. A. Cotton and G. Wilkinson, Advanced Inorganic Chemistry: A Comprehensive Text, John Wiley \& Sons, 4th edn, 1980.

28 A. Prescimone, J. Sanchez-Bentez, K. V. Kamenev, J. E. Warren, A. R. Lennie, M. Murrie, S. Parsons and E. K. Brechin, Z. Naturforsch., B: Chem. Sci., 2010, 65, 221; S. R. Cooper and M. J. Calvin, J. Am. Chem. Soc., 1977, 99, 6623.

29 S. Natarajan, B. R. Srinivasan, J. K. Sundar, K. Ravikumar, R. V. Krishnakumar and J. Suresh, J. Chem. Sci., 2012, 124, 781.

30 L.-C. Yu, Z.-F. Chen, H. Liang, C.-S. Zhou and Y. Li, J. Mol. Struct., 2005, 750, 35.

31 S. H. Dale and M. R. J. Elsegood, Acta Crystallogr., Sect. C: Cryst. Struct. Commun., 2003, 59, m540.

32 M.-X. Li, G.-Y. Xie, Y.-D. Gu, J. Chen and P.-J. Zheng, Polyhedron, 1995, 14, 1235.
33 E. Bartolomé, J. Bartolomé, S. Melnic, D. Prodius, S. Shova, A. Arauzo, J. Luzón, F. Luis and C. Turta, Dalton Trans., 2013, 42, 10153.

34 R. Schenker, M. N. Leuenberger, G. Chaboussant, D. Loss and H. U. Güdel, Phys. Rev. B: Condens. Matter, 2005, 72, 184403.

35 D. L. Huber, Phys. Rev. B, 1965, 139, A1684.15.08.2013.

36 A. C. Anderson and J. E. Robichaux, Phys. Rev. B: Solid State, 1971, 3, 1410.

37 M. Orendáč, L. Sedláková, E. Čižmár, A. Orendáčová, A. Feher, S. A. Zvyagin, J. Wosnitza, W. H. Zhu, Z. M. Wang and S. Gao, Phys. Rev. B: Condens. Matter, 2010, 81, 214410.

38 A. Arauzo, A. Lazarescu, S. Shova, E. Bartolomé, R. Cases, J. Bartolomé and C. Turta, Dalton Trans., 2014, 43, 12342.

39 K. D. Magers, C. G. Smith and D. T. Sawyer, Inorg. Chem., 1978, 17, 515.

40 Y. Sato and N. Tanaka, Bull. Chem. Soc. Jpn., 1968, 41, 2064.

41 E. Y. Tsui, R. Tran, J. Yano and T. Agapie, Nat. Chem., 2013, $5,293$. 